\title{
PENERAPAN PEMBELAJARAN PENDIDIKAN AGAMA ISLAM BERBASIS SAINS BUDAYA LOKAL DI SEKOLAH DAN MADRASAH
}

\author{
Firman Mansir*, Halim Purnomo, Tumin \\ Universitas Muhammadiyah Yogyakarta, Indonesia \\ *E-mail: firmanmansir@umy.ac.id
}

\begin{abstract}
This article examines the application of science and culture-based Islamic Education at school and madrasa. This research refers to application of natural science which is related to the Indonesian local culture by giving priority to the values in Islam. This research aims to search for and research about the applied science by pairing or linking it with Indonesian culture. In its process, this research is not directing the learning of Islamic Religious Education to either the qualitative, quantitative or mix of them, but this learning can use one or even both of them in its learning methodology. This research discusses the application of learning that leads to science and refers to Indonesian culture by considering at Islamic values. It can be referred to as observations of habits tanght and practiced in the learning process activities in schools and madrasas.
\end{abstract}

Keywords: Learning, Islamic Education, Science, Culture

\begin{abstract}
Abstrak. Artikel ini mengkaji penerapan pembelajaran Pendidikan Agama Islam di sekolah dan madrasah yang berbasis sains dan budaya. Penelitian ini mengarah kepada penerapan sains atau ilmu pengetahuan alam yang dikaitkan dengan budaya lokal di Indonesia khususnya dengan mengutamakan nilai-nilai yang ada di dalam Islam. Tujuan dari penelitian ini adalab untuk. mencari dan meneliti tentang ilmu sains yang diterapkan dengan menyandingkan atau mengkaitkan dengan budaya Indonesia. Dalam prosesnya, penelitian ini bukan mengarabkan pembelajaran Pendidikan Agama Islam pada ranah kualitatif dan kuantitatif atau penggabungan namun pembelajaran ini bisa menggunakan salah satu babkan kedua-duanya dalam metodologi pembelajarannya. Kajian ini membahas penerapan pembelajaran yang mengarah pada sains dan kebudayaan Indonesia dengan melihat nilai-nilai keislaman. Hal it dapat disebut sebagai hasil pengamatan kebiasaan yang diajarkan dan dipraktekkan pada kegiatan proses pembelajaran di sekolah dan madrasah.
\end{abstract}

Kata Kunci: Pembelajaran, Pendidikan Agama Islam, Sains, Budaya. 


\section{PENDAHULUAN}

Islam merupakan agama yang diturunkan oleh Allah SWT melalui malaikat yang taat dan dipercaya sesuai dengan tugasnya salah satunya malaikat Jibril yang bertugas untuk menyampaikan wahyu kepada makhluk pilihan-Nya. Allah SWT menurunkan Islam melalui perantara Nabi Muhammad SAW yang merupakan makhluk ciptaan Allah SWT yang sangat mulia dan sangat dicintai oleh-Nya (wahidin, unang; Ahmad, 2018). Dikaitkan dengan pendidikan, Islam juga dianjurkan dan diperintahkan untuk memberikan sebuah wawasan dan cakrawala pengetahuan tentang berbagai sumbersumber ilmu pengetahuan yang mendalami tentang Islam. Sebagaimana Nabi Muhammad SAW diutus oleh Allah SWT untuk memberikan syiar Islam dan membenarkan kehidupan yang sebelumnya dikatakan sangat jauh sekali dengan kehidupan yang benar, bahkan ajaran-ajaran yang menyesatkan para umat pun sangatlah besar dan belum bisa diatasi (Rerung, Sinon, \& Widyaningsih, 2017).

Penerapan merupakan langkah, tindakan atau bukti dalam melakukan setiap kegiatan ataupun aktivitas yang nantinya akan dapat dilihat dan dirasakan bagi setiap orang. Penerapan juga bisa diartikan sebagai kebiasaan dalam melakukan hal-hal untuk menghasilkan sebuah pengalaman yang didapat dan akan membuahkan sebuah perubahan yang baik atau pun buruk (Idrus Hariri \& Mulyani, 2016). Pembelajaran bisa dikatakan sebagai kegiatan yang dilakukan oleh seorang pendidik yang bertujuan untuk memberikan suplemen ilmu dan pengetahuan yang belum didapatkan kepada siswanya (Zainal, 2008). Pembelajaran adalah sebuah rencana yang akan diolah dengan menggunakan model dan strategi yang sudah disiapkan dan nanti terjadi sebuah bukti hasil yang telah dilaksanakan. Pengolahan tersebut tidak lepas dengan proses terjadinya interaksi yang baik antara pendidik dengan peserta didik (Pane \& Darwis Dasopang, 2017).

Cara dalam mengkoordinasikan dan pembagian waktu setiap aktivitas, baik dari proses pembuatan program kerja sampai dengan penguasaan dalam mengahadapi peserta didik itu sangat dilihat dengan kepribadian dan kehidupan yang tertata dari pendidik tersebut. Pasti nantinya peserta didik akan bisa merasakan dan menilai apa yang telah didapatkan selama peserta didik tersebut menuntut ilmu di sekolah tersebut (Fakhrurrazi, 2018). Sains dilahirkan dari kata scientia diartikan menjadi "saya tahu". Yang tercantum di dalam Kamus Bahasa Inggris, kata sains adalah science artinya cakrawala (Maknun, 2017). Sains bisa disimpulkan bahwa ilmu yang mendalami dan mengkaji lebih luar dan lebih mendalam lagi dengan melihat penyebab yang menjadi titik masalah dan juga akibat yang terjadi permasalahan di alam yang Allah SWT ciptakan. Sains yang mendalami dan membahas tentang keilmuan dalam bidang alam, mempunyai satu kesatuan dengan melakukan pencarian titik sumber tentang alam secara obyektif. Maka dari itu, sains tidak hanya sebagai pengatur dan tidak hanya 
sebagai titik pembahasan yang hanya terfokus kedalam pengetahuan saja yang terdiri dari konsep yang terstruktur, fakta yang aktual atau prinsip yang jelas, itu sebagai inti dari suatu tindakan dalam penemuan.

Sains yang lebih condong dalam ilmu alam merupakan pemikiran dan penguasaan materi yang disampaikan oleh manusia melalui interaksi berkomunikasi yang akan menghasilkan sebuah data dan modal untuk dijadikan sebagai bahan penelitian. Yang dilakukan dengan menggunakan cara mengkunjungi tempat yang akan dijadikan sebagai obyek tujuan penelitian dan juga tempat untuk melakukan sebuah ciptaan yang baru secara tertata, begitu juga harus menyertakan bahan materi yang digunakan sebagai pengikat dan penguat dari hasil penelitian tersebut, seperti perihal hukum, prinsip, aturan, hipotesa dan teori (Hidayatullah, 2019).

Ilmu Pengetahuan Alam atau sains adalah sebuah ilmu yang lebih menjerumus kearah ilmu alam dan fokus pada titik materi pembahasan tersebut dengan melihat bagaimana proses terjadinya yang ada di setiap fenoma alam yang terjadi. Sains dijelaskan sebagai suatu alat kontrol yang bertujuan untuk lebih meneliti dan mendalami alam jagad raya ini. Tujuan yang diharapkan dari proses pembelajaran sains ialah supaya bisa menjadi wadah untuk peserta didik dalam mempelajari diri pribadi dan begitu juga alam yang berada di sekitar. Dengan mempunyai target untuk melihat sampai mana perkembangan peserta didik dalam melakukan aktivitas sehari-hari. Mengkaji literasi sains ini juga sebagai kemampuan dalam memakai sumber pengetahuan secara ilmiah, mengkaji pertanyaan dan memberikan daya Tarik tersendiri dalam menyimpulkan beradasarkan fakta yang konkrit dan data yang jelas dan lengkap, memperhatikan setiap kejadian di alam semesta ini dan juga melakukan pembuatan keputusan dari dampak masalah dan kejadian yang terjadi karena kegiatan yang dilakukan oleh manusia (Ratnawati, Rahayu, \& Prayitno, 2010).

Negara Indonesia sebuah negara yang memiliki keajaiban alam yang sangat memukai dimata dunia. Hal yang membuat Indonesia adalah bagian dari negara yang ada di dunia dan menjadi negara yang memiliki kepulauan terbesar di dunia. Bisa dilihat, penduduk Indonesia sekarang tidak hanya masyarakat asli pribumi saja, tetapi berbagai ras dan keturunan dari berbagai belahan dunia itu ada di dalam negara Indonesia ini. Maka Indonesia mempunyai semboyan yang ada pada lambang burung Garuda yang menjadi sebuah maskot atau tanda lambang kebesaran Negara Republik Indonesia yaitu Bhineka Tunggal Ika yang artinya berbeda-beda tetap satu jua. Itu adalah sebuah landasan dan juga semangat bagi masyarakat Indonesia untuk saling hormat-menghormati dan juga yang terpenting saling menghargai satu dengan yang lain. Karena Allah Yang Maha Penguasa adalah yang memiliki dan menciptakan bumi dan juga planet-planet yang berada diluar angkasa ini. Allah SWT yang memberikan akal pikiran dan hati manusia untuk selalu melaksanakan dan mengingat perintah yang Allah anjurkan dan yang Allah perintahkan 
melalui perantara Nabi Muhammad SAW.

Budaya asli Indonesia, sejarah awal muncul di tanah nusantara ini dilahirkan pada masa lampau yang sudah ada pada zaman nenek moyang. Mereka pada dahulu kala, hidup dengan berbagai cara dan berbagai pemikiran untuk menghidupi kehidupan mereka sendiri. Budaya di Indonesia sudah memasuki masa era Globalisasi, di era ini budaya Indonesia yang asli dari zaman nenek moyang, dengan berjalannya waktu akan hilang dan bahkan diambil oleh negara lain. Kearifan asli Indonesia ini menjadi sebuah sumber dan acuan dalam Pendidikan juga untuk mencapai citra dan kecerdasan anak dengan mengedepankan nilai-nilai moral, budaya, adat istiadat, tradisi dari setiap daerah mereka tinggal, agama, seni dan sejarah. Dalam Pendidikan yang formal contohnya di sekolah dibawah Dinas Pendidikan ataupun Pendidikan yang informal contohnya Yayasan atau Lembaga Pendidikan yang dibawa naungan kelompok atau pribadi kearifan lokal juga masuk kedalam materi pendidikan tersebut atau aktivitas keseehariannya di sekolah. Jadi, dapat disimpulkan bahwasannya tradisi yang sudah melekat dan sudah ada di dalam diri masyarakat sendiri, maka itu sudah sebagai kepercayaan dan kebiasaan masyarakat itu sendiri. Maka dari itu sebagai masyarakat yang mempunyai etika dan budi pekerti yang luhur harus bisa memberikan rasa aman dan tentram, serta menjunjung tinggi nilai persaudaraan dan solidaritas yang baik antar masyarakat yang telah meluas dan mengedepankan pada tatanan budaya dan sosial (Jayana, 2018).

\section{METODE PENELITIAN}

Penelitian ini merupakan kualitatif, dengan menggunakan metode pengumpulan data melalui observasi atau pengamatan langsung (Prihatsanti, Suryanto, \& Hendriani, 2018). Di samping itu, untuk menambah data yang lebih akurat, peneliti menggunakan wawancara dengan beberapa guru yang telah ditunjuk sebelumnya untuk menjadi narasumber (Hakim, 2013). Wawancara yang digunakan adalah tanpa batas dan terdepan, dimana wawancara ini memadukan antara wawancara tanpa batas dengan wawancara terdepan. Jadi penggunaan cara dengan menggabungkan keduanya dilakukan dengan metode pengambilan instrumen ataupun data yang menggunakan pedoman dari wawancara yang ada (Rosaliza, 2015).

Dalam melakukan pengambilan data, peneliti sudah membuat rancangan dan angket yang sudah dibuat. Peneliti berusaha untuk mencari dan menggali informasi lebih detail dan jelas supaya dalam proses penyusunan penelitian dapat tertata rapi dan efektif. Teknik yang diambil dan digunakan oleh peneliti dalam proses pengambilan data yaitu melakukan wawancara dengan narasumber yang telah ditentukan. (Rijali, 2019). Dalam menganalisis data ini, peneliti menggunakan berbagai metode yang akan digunakan untuk menjadi cara yang sesuai dengan kecapaian yang diinginkan. Data yang sudah terkumpul dan dijadikan 
menjadi satu, maka selanjutnya ialah pengelolaan data dan menganalisis data yang sudah terkumpul pada saat melakukan pengambilan data. Langkah awal yang harus dilakukan dalam menganalisis data adalah melakukan koding. Koding merupakan langkah yang paling dasar untuk mengoperasionalisasi analisis data yang mengarah ke penelitian kualitatif. Sampai pada tahap koding ini, maka data lapangan yang sebelumnya sudah melakukan pengambilan data dalam observasi penelitian dan telah dikumpulkan sesuai dengan masingmasing pembahasan (Irkhamiyati, 2017).

\section{HASIL PENELITIAN DAN PEMBAHASAN}

Negara Indonesia dalam catatan dunia disebut sebagai negara kepulauan terbesar di dunia yang berada di negara ASEAN atau di Asia Tenggara. Dengan memiliki pulau dengan jumlah 17.508 pulau yang terbentang di Indonesia dengan total seluruhnya luas wilayah pulau Indonesia adalah sebesar $1,904,569 \mathrm{~km}^{2}$. Indonesia dibilang negara yang sangatlah unik dan mempunyai ciri khas tersendiri. Dengan memiliki pulau-pulau yang paling utama Indonesia yaitu Pulau Papua, Pulau Sulawesi, Pulau Kalimantan, Pulau Sumatra dan Pulau Jawa. Disebut Negara Kepulauan Terbesar di dunia, Indonesia merupakan salah satu negara dari sekian ratus negara di dunia yang mempunyai garis pantai terpanjang di dunia.

Indonesia adalah sebuah negara yang ditakdirkan dan diciptakan oleh
Allah yang Maha Pencipta dan Maha Segalanya, karena bisa dilihat dengan bukti nyata Allah SWT memberikan sebuah ciptaan yang sangat indah dan sangat menakjubkan bagi manusia yang ditakdirkan untuk turun dimuka bumi ini. Indonesia adalah negara maritim, dilihat dari ekosistem alamnya yang sangat banyak dan sangat kaya. Bisa dilihat kembali ke belakang tentang sejarah awal terbentuknya Indonesia. Indonesia negara yang dijajah, ditindas dan dirampas harta kekayaan alam yang sangat belimpah ruah dan bahkan rakyat Indonesia asli pun dijadikan sebagai budak atau pekerja bagi para penjajah Belanda, Jepang dan Portugis sendiri. Betapa kayanya Indonesia sampai negara asing juga berani untuk datang dan menginjakkan kaki di tanah Indonesia untuk berniat memiliki hak dan wewenang dalam urusan yang meliputi ekonomi, politik, dan hukum pada saat itu (Budi Setyaningrum, 2018).

Indonesia disebut sebagai negara sejuta warna dan sejuta jiwa karena memiliki berbagai aneka ragam jenis dari agama, suku, ras, bahasa, dan budayanya. Dengan ditambah pesona alam jagad raya di Indonesia ini, menjadi nilai plus bagi negara Indonesia. Belajar dalam ilmu sains lebih diarahkan kepada keinginan untuk mencapai pemahaman dan penguasaan dalam bidang ilmu sains atau bisa dengan berpegang pada konsep tertentu. Supaya peserta didik dapat mengingat dan mencerna dengan konsep-konsep yang ada di dalam ilmun sains tersebut. Namun, tidak bisa digunakan untuk menerapkan setiap konsep yang ada 
dan yang telah dipelajari dalam menghadapi setiap masalah dalam kehidupan itu sendiri. Jadi, proses pembelajaran lebih menekankan kearah penguasaan salah satu konsep dari sekian banyaknya konsep dari ilmu sains, itu akan menyebabkan peserta didik mengalami pengolahan materi yang ada diotak dengan kritis secara tidak berkembang dan tidak maksimal. Maka, nantinya akan dilakukan evaluasi pembelajaran untuk bisa melihat apakah ada kendala dan masalah ataupun baik-baik saja tanpa ada suatu halangan apapun (Majdi, 2019).

Budaya dan proses dari belajar merupakan dua hal yang sangat berkaitan dan tidak bisa dilepaskan antar keduanya. Dikarenakan keterkaitannya dengan budaya sangat menunjang secara baik dalam proses kegiatan pembelajaran. Apabila dalam pembelajaran sains yang dilaksankan di sekolah dan tidak menghiraukan dan tidak melihat budaya bagi peserta didik, maka yang akan didapatkan konsekuensinya ialah peserta didik ingin memilih menolak atau menerima sebagian bentuk dan konsep sains yang akan dilanjutkan dan ditingkatkan dalam pembelajaran. Langkah untuk menginternalisasikan salah satu budaya yang diangkat kedalam pembelajaran adalah salah satu taktik dalam melakukan perencanaan untuk meningkatkan kualitas dan kreatifitas berpikir peserta didik dengan cara melakukan pendekatan secara terperinci sebagai rancangan proses belajar dikaitkan dengan pengetahuan dan sumber sesuai dengan dunia nyata (Yunus, 2016). Sehingga peserta didik bisa melakukan hubungan secara tertata dengan pengetahuan yang didapatkan. Taktik rencana yang sudah dirancang akan memberikan sebuah rasa dan pengalaman dalam pengembangan kreatifitas misalnya dalam menggunakan otak untuk berpikiran jelas dan kritis (Rahayu, 2014).

Oleh karena itu, model pembelajaran yang digunakan dan dijadikan sebuah praktek untuk proses pembelajaran salah satunya yaitu inkuiri terbina, hal ini juga dikatakan sebagai model dalam proses pembelajaran yang mengedepankan pada program pencarian dan memaparkan hubungan antara obyek dan keadaan (Mubah, 2011). Bentuk pembelajaran inkuiri terbimbing berupa memberi motivasi kepada siswa untuk menyelidiki masalahmasalah yang ada dengan menggunakan cara-cara keterampilan ilmiah dalam rangka mencari penjelasan-penjelasannya sehingga dapat membantu siswa menjadi lebih mandiri dan bertanggung jawab. Siswa akan bangkit dan semangat ketika mereka belajar membuka dan mendapatkan sesuatu oleh dirinya sendiri, dibandingkan dengan mendengarkan apa yang dikatakan oleh guru. Mereka belajar melakukan aktivitas dengan otonomi sendiri dan menjadi seorang yang inner-directed. Siswa belajar memanipulasi lingkungannya lebih aktif.

Dalam kegiatan belajar mengajar berlangsung peran guru sebagai pembimbing adalah dengan memberikan petunjuk-petunjuk bila dibutuhkan. Selama siswa tidak membutuhkan bantuan, siswa dibiarkan bekerja dalam kelompok 
belajaranya secara mandiri. Dalam pembelajaran ini siswa dilatih mengembangkan fakta-fakta, membangun konsep-konsep, dan yang menjadi daya tarik dari kesimpulan umum atau teori-teori yang menjelaskan tentang fenomena yang membudidayakan kreatifitas dan inovasi dalam penemuan ilmiah atau dalam bahasa Inggris dikatakan scientific inquiry pada siswa siswa. Ruang lingkup dalam praktek pembelajaran seperti ini, tentunya akan membuat siswa termotivasi untuk belajar, karena dalam kegiatan pembelajaran mereka dapat belajar menemukan sesuatu oleh dirinya sendiri. Dengan demikian proses pembelajaran yang dilakukan akan menjadi lebih bermakna bagi diri siswa. Selain itu, adanya energi dengan budaya yang didaptkan dan dipunyai oleh siswa dan ilmu-ilmu yang akan dimantapkan untuk dibaca dan dipelajari dapat membantu siswa untuk lebih mudah dalam memahami materi pembelajaran (Ni Putu Marheni, 2014).

Melakukan pengkajian ilmu sains dengan berbasis kearifan lokal dan mengambil di suatu daerah, yang paling diutamakan dan yang lebih direncanakan apa model pembelajaran yang akan digunakan. Dengan menggunakan cara membangun dan menggali ilmu sains asli, akan lebih bisa membandingkan dan juga mengetahui seberapa besar kontribusi sains dengan mengkaitkan kebudayaan yang asli Indonesia. Yang dimaksud dengan membangun dan menggali ilmu sains asli ini adalah konsepkonsep yang sudah tercantum dan diciptakan dalam sains barat atau sains barat untuk dilakukan penataan kembali supaya bisa menjadi landasan dalam pengkajian (Pieter, 2016). Dalam melakukan penlitian dengan cara berkunjung atau observasi ilmu sains asli ini, dilakukan dengan melihat dan memilih tempat atau obyek penelitian yang berkaitan dengan kebudayaan di masyarakat Indonesia. Maka, bisa disimpulkan bahwa model pembelajaran yang mengkaitkan sains asli dengan kearifan lokal didapatkan dari pengalaman dan pengetahuan dari masyarakat asli atau bisa dikatakan sebagai tokoh masyarakat yang mengerti dan mengetahui silsilah dari awal terjadinya suatu peristiwa kebudayaan yang sampai sekarang masih dilaksanakan. Tradisi dari nilai budi pekerti yang luhur itu sebuah kunci dalam tatanan masyarakat dalam menjaga kebudayaan asli, tujuan yang paling utama untuk (Khusniati, 2014).

\section{KESIMPULAN}

Terdapat keterkaitan antara pembelajaran Pendidikan Agama Islam dengan basis sains digabungkan dengan kearifan lokal atau budaya asli Indonesia, apalagi jika ditambah dengan nilai-nilai dalam ajaran Islam. Sains merupakan ilmu yang mendalami tentang proses terjadinya fenomena alam yang ada di muka bumi ini dan berusaha mengungkapkan kejadian fenomena yang terkandung dalam ilmu sains yang dijabarkan melalui metode ilmiah. Dikaitkan dengan budaya, ilmu sains juga memasukan budaya dalam pembahasan materi di dalamnya, karena budaya masuk dalam karakteristik ilmu sains. Adapun yang dimaksud dengan budaya di sini adalah sebuah pembahasan materi yang 
mengkaji tentang landasan dan dasardasar kebudayaan. Di Indonesia negara yang disebut sebagai negara kepulauan terbesar di dunia memiliki ekosistem dan dan sumber daya alamnya yang melimpah ruah, apalagi masyarakat di Indonesia mayoritas beragama Islam. Dalam bidang pendidikan, Indonesia sangat mengedepankan nilai-nilai moral, budi pekerti yang luhur dan juga kerohaniaannya. Karena itu semua adalah kunci utama dan pegangan dalam hidup masyarakat Indonesia untuk bisa menjadikan contoh teladan yang baik dan benar bagi semua orang dan juga bisa dijadikan sebagai jalan untuk mengantarkan dirinya sendiri menuju masa depan yang cerah dan yang diinginkan. Dengan mengutamakan nilai-nilai keislaman maka itu semua akan terencana dengan baik dan pemikiran yang terbangun akan jelas hasilnya.

\section{REFERENSI}

Idrus Hariri, A., \& Mulyani, A. (2016). Penerapan Pembelajaran Berbasis Sains Budaya Lokal Ngaseup Pada Konsep Sistem Reproduksi Manusia Untuk Meningkatkan Keterampilan Berpikir Kritis Siswa Kelas Xi Sman 1 Maja. Jurnal Sains Dan Pendidikan Sains Scientiae Educatia, 5(1), 1-14. Retrieved from www.syekhnurjati.ac.di/jurnal/in dex.php/sceducatia

Mubah, A. S. (2011). Strategi Meningkatkan Daya Tahan Budaya Lokal dalam Menghadapi Arus Globalisasi. Jurnal Unair, 24(4), 302-308. https://doi.org/10.1159/0003221 38

Majdi, A. L. (2019). Ilmu pengetabuan (sains): dialektika paradigmatis barat dan islam. (January).

Wahidin, unang; Ahmad, S. (2018). Jurnal Edukasi Islami Jurnal Pendidikan Islam Vol . 07 / No .1 , Teori-Teori Pendidikan ... Teori-Teori Pendidikan .... Jurnal Pendidikan Islam, 07(1), 47-66. https://doi.org/10.30868/EI.V7

Raehang. (2014). Pembelajaran Aktif Sebagai Induk Pembelajaran Kooperatif. Jurnal Al-Ta'dib, 6(1), 149-167. Retrieved from ejournal.iainkendari.ac.id/altadib/article/view/249/239

Budi Setyaningrum, N. D. (2018). Budaya Lokal Di Era Global. Ekspresi Seni, 20(2), 102. https://doi.org/10.26887/ekse.v2 $0 \mathrm{i} 2.392$

Fakhrurrazi, F. (2018). Hakikat Pembelajaran Yang Efektif. AtTafkir, 11(1), 85. https://doi.org/10.32505/at.v11i 1.529

Nurkholis. (2013). PENDIDIKAN DALAM UPAYA MEMAJUKAN TEKNOLOGI Oleh: Nurkholis Doktor Ilmu Pendidikan, Alumnus Universitas Negeri Jakarta Dosen Luar Biasa Jurusan Tarbiyah STAIN Purwokerto. Jurnal Kependidikan, 1(1), 24-44.

Pane, A., \& Darwis Dasopang, M. (2017). Belajar Dan Pembelajaran. FITRAH: Jurnal Kajian Ilmu-Imu Keislaman, 3(2), 333. https://doi.org/10.24952/fitrah.v 3i 2.945 
Yanuar Bagas Arwansyah, Sarwiji Suwandi, S. T. W. (2016). Revitalisasi Peran Budaya Lokal dalam Materi Pembelajaran Bahasa Indonesia bagi Penutur Asing (BIPA). Makalah, (1), 915920.

Rahayu, A. (2014). Volume 02 nomor 01 maret 2014. Jurnal Pendidikan Sains Universitas Mubammadiyah Semarang, 02(01), 6-13.

Suastra, I. W. (1999). Model Pembelajaran Sains Berbasis Budaya Lokal. Jurnal Pendidikan Dan Pembelajaran, 43(2), 8-16. https://doi.org/10.1063/1.16359 72

Maknun, J. (2017). Konsep Sains dan Teknologi pada Masyarakat Tradisional di Provinsi Jawa Barat, Indonesia. Konsep Sains Dan Teknologi Pada Masyarakat Tradisional Di Provinsi Jawa Barat, Indonesia, 2(2), 127-142. https://doi.org/10.17509/mimba rdik.v2i2.8623

Prayogi, R., \& Danial, E. (2016). Pergeseran Nilai-Nilai Budaya Pada Suku Bonai Sebagai Civic Culture Di Kecamatan Bonai Darussalam Kabupaten Rokan Hulu Provinsi Riau. Humanika, 23(1), 61. https://doi.org/10.14710/human ika.23.1.61-79

Zainal, A. and. (2008). Konsep Manajemen Kelas dan Implikasinya dalam Pembelajaran. Jurnal Kependidikan, 2(2), 30-46.

Yunus, R. (2016). Transformasi NilaiNilai Budaya Lokal Sebagai Upaya Pembangunan Karakter Bangsa. Jurnal Penelitian Pendidikan, 13(1).
Musanna, A. (2017). INDIGENISASI PENDIDIKAN: Rasionalitas Revitalisasi Praksis Pendidikan Ki Hadjar Dewantara INDIGENIZING

EDUCATION: Rationalization toward Revitalization of $\mathrm{Ki}$ Hadjar Dewantara Educational Praxis. Pendidikan Dan Kebudayaan, 2(1), 117-133. Retrieved from http://jurnaldikbud.kemdikbud.g o.id/index.php/jpnk/article/view $/ 529$

Ratnawati, E., Rahayu, S., \& Prayitno. (2010).

PEMAHAMAN HAKIKAT SAINS (NOS) MAHASISWA TAHUN KETIGA PROGRAM STUDI PENDIDIKAN KIMIA UNIVERSITAS NEGERI MALANG Eris. Universitas Negeri Malang, (2006), 1-15.

Jayana, T. A. (2018). Relasi Sains, Budaya, dan Agama Upaya Pendekatan Paradigma Yang Menyatukan. Al-MAIYYAH: Media Transformasi Gender Dalam Paradigma Sosial Keagamaan, 11(1), 153-170.

https://doi.org/10.35905/almaiy yah.v11i1.550

Pieter, J. (2016). Pembelajaran Ipa Berbasis Kearifan Lokal Sebagai Solusi Pengajaran Ipa Di Daerah Pedalaman Provinsi Papua. Prosiding Seminar Nasional Pendidikan UNCEN Tabun 2016, (March 2016), 44-54. https://doi.org/10.5281/zenodo. 840857

Rerung, N., Sinon, I. L. S., \& Widyaningsih, S. W. (2017). Penerapan Model Pembelajaran Problem Based Learning ( PBL ) 
untuk meningkatkan Hasil Belajar. Jurnal Ilmiah Pendidikan Fisika AlBiruNi, 06(April), 47-55. https://doi.org/10.24042/jipf

Hidayatullah, S. (2019). Agama dan Sains: Sebuah Kajian Tentang Relasi dan Metodologi. Agama Dan Sains: Sebuah Kajian Tentang Relasi Dan Metodologi, 29(1), 102133.

https://doi.org/10.22146/jf.3024 6

Ni Putu Marheni, I. N. S. (2014). 87 PEMBELAJARAN INKUIRI TERBIMBING BERBASIS BUDAYA LOKAL PADA PEMBELAJARAN SAINS KIMLA SMP Ni Putu Marheni, I Nyoman Suardana. 8, 87-100.

Wahidmurni. (2017). Pemaparan Metode Penelitian Kuantitatif. العدد رجلة اسيوط للار/سات البيئة الحابs), 43. https://doi.org/10.1017/CBO97 81107415324.004

Prihatsanti, U., Suryanto, S., \& Hendriani, W. (2018). Menggunakan Studi Kasus sebagai Metode Ilmiah dalam Psikologi. Buletin Psikologi, 26(2), 126.

https://doi.org/10.22146/buletin psikologi.38895

Irkhamiyati. (2017). Evaluasi Persiapan Perpustakaan Stikes Aisyiyah Yogyakarta. Berkala Ilmu Perpustakaan Dan Informasi, 13(1), 37-46.

Rijali, A. (2019). Analisis Data Kualitatif. Alhadharab: Jurnal Ilmu Dakwah, $\quad$ 17(33), 81. https://doi.org/10.18592/alhadh arah.v17i33.2374
Hakim, L. N. (2013). Ulasan Metodologi Kualitatif: Wawancara Terhadap Elit. Aspirasi: Jurnal Masalah-Masalah Sosial, 4(2), 165172. Retrieved from https://jurnal.dpr.go.id/index.ph $\mathrm{p} /$ aspirasi/article/view/501

Rosaliza, M. (2015). Wawancara, Sebuah Interaksi Komunikasi Dalam Penelitian Kualitatif. Jurnal Ilmu Budaya, Vol. 11, pp. 71-79. https://doi.org/10.31849/jib.v11i 2.1099 